\title{
Chorionic surface area in conceptuses from sows treated with progesterone and oestrogen during early pregnancy*
}

\author{
P. T. McGovern, C. B. Morcom, W. F. de Sa and W. R. Dukelow \\ Department of Anatomy, and The Endocrine Research Unit, Michigan State University, \\ East Lansing, Michigan 48824, U.S.A.
}

\begin{abstract}
Summary. Treatment of sows with $25 \mathrm{mg}$ progesterone and $12.5 \mu \mathrm{g}$ oestrone daily between 14 and 23 days of gestation resulted in an increase of $15 \%$ of chorionic surface area and an increase in volume of allantoic fluid when examined at 30-35 days of gestation. In contrast, there were no significant differences in chorionic surface area or allantoic fluid volume between treated and control sows examined at 46-50 days of gestation. This suggests that progesterone-oestrone treatment of the sows during early pregnancy has only a short-lived effect on development of the allantochorion.
\end{abstract}

\section{Introduction}

The level of prenatal mortality in the pig has prompted several investigations into the effect on embryo survival of treating the dam with steroid hormones during the early part of pregnancy. Administration of progesterone alone has no effect on embryo survival or, when high doses are used, is not associated with an increase in embryonic mortality (Sammelwitz, Dziuk \& Nalbandov, 1956; Haines, Warnick \& Wallace, 1958; Spies, Zimmerman, Self \& Casida, 1959). By contrast, administration of progesterone and oestrogen (oestrone or oestradiol) in a 2000:1 ratio results in an increase in the number of live embryos in the uteri of gilts examined at about mid-pregnancy (Reddy, Mayer \& Lasley, 1958; Day, Anderson, Emmerson, Hazel \& Melampy, 1959). The results of two field trials undertaken by Wildt, Culver, Morcom \& Dukelow (1976) also indicated that treatment of sows with progesterone and oestrone $(2000: 1)$ during early pregnancy had a beneficial effect on embryo survival, although the findings were not wholly unequivocal. In the main trial, an increase of approximately $20 \%$ in litter size at birth was recorded in the treated animals, but in a second trial no significant difference was observed between the treated and control groups.

It is not known whether the putatively beneficial effect of the progesterone-oestrogen treatment in early pregnancy is associated with an increase in the number of embryos that implant or with uterine changes that enhance placental development thereby reducing the incidence of prenatal mortality during the subsequent stages of gestation. In view of the latter possibility, we have compared the development of the fetal membranes of conceptuses of treated and non-treated sows.

" Reprint requests to: Dr W. R. Dukelow, Endocrine Research Unit, Michigan State University, East Lansing, Michigan 48824, U.S.A. 


\section{Materials and Methods}

The animals were multiparous Yorkshire-Hampshire-Duroc crossbred sows of 18-30 months of age. The sows were mated to Duroc or Yorkshire boars on the first and second days of oestrus, and were assigned alternately to the control (17 animals, $163-212 \mathrm{~kg}$ body wt) or the treated (16 animals, $159-217 \mathrm{~kg}$ body wt) groups. All sows received a complete $13.0 \%$ protein ration of 1.8 $\mathrm{kg} /$ animal/day from the day of mating until slaughter.

Solutions of $25 \mathrm{mg}$ progesterone (Sigma Chemical Co., St Louis, Missouri) and $12.5 \mu \mathrm{g}$ oestrone (Sigma Chemical Co.) per $2.0 \mathrm{ml}$ arachis oil were prepared according to the description of Reddy et al. (1958). The sows in the treated group were each given $2.0 \mathrm{ml}$ progesterone-oestrone solution daily by intramuscular injection from Day 14 to Day 23 of pregnancy (first day of oestrus = Day 1 of pregnancy). The sows in the control group were each given $2.0 \mathrm{ml}$ arachis oil daily by intramuscular injection over the same period.

The sows were slaughtered between Days 30 and 35 of pregnancy or between Days 46 and 50 of pregnancy. The reproductive tracts were recovered for examination, and the numbers of corpora lutea and conceptuses were recorded. After removal from the uterus, each conceptus was placed on paper and a tracing made of the allantochorionic sac. In the conceptuses examined at Days 46-50, the positions of the placental-paraplacental junction and of the paraplacental-ischaemic zone junction were noted. The values recorded for total chorionic surface area and for placental and paraplacental surface area were later calculated by doubling the planimeter readings obtained from the tracings. Counts were made of the areolae in three different $3 \mathrm{~cm}^{2}$ areas of the placental region of each conceptus. Data were also collected on the weight of fetal membranes, amniotic fluid volume, fetal weight, and crown-rump length of the fetuses.

\section{Results and Discussion}

The results are summarized in Tables 1 and 2.

Table 1. Prenatal mortality in control and steroid-treated sows examined between Days 30 and 35 or between Days 46 and 50 of pregnancy

\begin{tabular}{|c|c|c|c|c|}
\hline Days of pregnancy & $\begin{array}{l}\text { No. of } \\
\text { sows }\end{array}$ & $\begin{array}{c}\text { No. of } \\
\text { corpora lutea/sow* }\end{array}$ & Live embryos/sow" & $\begin{array}{c}\text { Prenatal } \\
\text { mortality (\%) }\end{array}$ \\
\hline \multicolumn{5}{|l|}{ Control sows } \\
\hline $30-35$ & 9 & $16 \cdot 1 \pm 0.8$ & $12 \cdot 1 \pm 1 \cdot 5$ & $36 / 145(24.8)$ \\
\hline $46-49$ & 8 & $15.9 \pm 1.3$ & $11 \cdot 1 \pm 1.0$ & $38 / 127(29.9)$ \\
\hline \multicolumn{5}{|l|}{ Treated sows } \\
\hline $30-35$ & 9 & $16 \cdot 1 \pm 0.9$ & $12 \cdot 2 \pm 1 \cdot 4$ & $35 / 145(24 \cdot 1)$ \\
\hline $46-49$ & 7 & $17.0+1.0$ & $12.9+1.3$ & $29 / 119(24.4)$ \\
\hline
\end{tabular}

* Values are mean \pm s.e.m.

Although the numbers of sows in the present study were low the mean number of live fetuses per sow was not significantly greater in the treated animals at Days 30-35 or at Days 46-50. The findings thus differ from those of Reddy et al. (1958) and Day et al. (1959) and fail to resolve the uncertainty regarding the efficacy of the combined progesterone-oestrone treatment raised by the disparity between the results of the main and subsidiary field trials of Wildt $e t$ al. (1976).

The observations do, however, indicate that the treatment of pregnant sows with progesterone and oestrone is associated with changes in the fetal membrane of conceptuses at Days 30-35. The mean value for total chorionic surface area (the demarcation between placental, 
Table 2. Observations on the uterine contents of control and steroid-treated sows examined between Days 30 and 35 or Days 46 and 50 of pregnancy

\begin{tabular}{|c|c|c|c|c|}
\hline & \multicolumn{2}{|c|}{ Days $30-35$} & \multicolumn{2}{|c|}{ Days $46-50$} \\
\hline & $\begin{array}{l}\text { Control } \\
\text { sows }\end{array}$ & $\begin{array}{c}\text { Treated } \\
\text { sows }\end{array}$ & $\begin{array}{l}\text { Control } \\
\text { sows }\end{array}$ & $\begin{array}{c}\text { Treated } \\
\text { sows }\end{array}$ \\
\hline Placental surface area $\left(\mathrm{cm}^{2}\right)$ & $528 \pm 16 \cdot 2$ & $608 \pm 14 \cdot 6$ & $539.0 \pm 39.8$ & $531.0 \pm 40.8$ \\
\hline $\begin{array}{l}\text { Paraplacental surface area } \\
\left(\mathrm{cm}^{2}\right)\end{array}$ & - & - & $83 \cdot 0 \pm 4 \cdot 2$ & $81.0 \pm 4.4$ \\
\hline Areolae $/ \mathrm{cm}^{2}$ & - & - & $1.5 \pm 0.1$ & $1.6 \pm 0.1$ \\
\hline Weight of fetal membranes (g) & $32 \cdot 1 \pm 1 \cdot 3$ & $30 \cdot 3 \pm 1 \cdot 1$ & $87 \cdot 4 \pm 3 \cdot 3$ & $80.4 \pm 9.3$ \\
\hline A mniotic fluid (ml) & $2.5 \pm 0.1$ & $2.5 \pm 0.1$ & $26 \cdot 0 \pm 0.8$ & $27.0 \pm 0.7$ \\
\hline Allantoic fluid (ml) & $149.4 \pm 3.7$ & $201 \cdot 1 \pm 6 \cdot 6$ & $95 \cdot 0 \pm 8 \cdot 4$ & $81.0 \pm 11.0$ \\
\hline Weight of fetus $(\mathrm{g})$ & $2 \cdot 0 \pm 0 \cdot 1$ & $1.8 \pm 0.1$ & $32.4 \pm 1.1$ & $29.7 \pm 0.7$ \\
\hline Crown-rump length of fetus $(\mathrm{cm})$ & $2 \cdot 7 \pm 0.1$ & $2 \cdot 6 \pm 0.1$ & $7 \cdot 6 \pm 0.2$ & $7 \cdot 9 \pm 0.1$ \\
\hline
\end{tabular}

Values are mean \pm s.e.m./conceptus (see Table 1 for numbers of conceptuses involved).

paraplacental and ischaemic zones not being evident at this stage) was approximately $15 \%$ greater for the conceptuses from the treated sows than for those from the control animals $(t=$ 5.041, $P<0.001$ ). This observation is similar to findings of Knight, Bazer \& Wallace (1974) who noted a significant increase in the length of the chorionic sac of embryos from gilts which had been treated with progesterone. There was an apparent increase in the surface area of control animals between the earlier and later examination periods $\left(528\right.$ and $622 \mathrm{~cm}^{2}$ respectively); the latter value includes the placental and paraplacental areas, a division not possible at 30-35 days, but there was also a lower mean number of conceptuses at 45-50 days than at 30-35 days. There was no significant difference in placental and paraplacental surface area or number of conceptuses in the treated animals at the earlier and later examination periods.

The mean values for allantoic fluid volume at Days 30-35 were also greater for the treated animals $(t=5.041, P<0.001)$. In the pig, allantoic fluid volume undergoes a very rapid decrease during the 5 th week of gestation (Knight, Bazer, Thatcher, Franks \& Wallace, 1977), but the difference recorded here would not appear to reflect a sampling bias as the distribution of gestational ages was similar in the two groups (treated group: $4 \times 30,2 \times 31,2 \times 32,1 \times 35$; control group: $3 \times 30,3 \times 31,2 \times 33,1 \times 35$ ).

In contrast to the findings on the conceptuses examined at Days 30-35, no significant differences with respect to chorionic surface area or allantoic fluid volume were observed in the conceptuses from the treated and control sows examined at Days 46-50 (see Table 2). Progesterone-oestrone treatment of the sows during early pregnancy therefore appears to have only a short-lived effect on the development of the allantochorion. Moreover, the fact that no significant differences in prenatal mortality or fetal size were observed between the treated and control animals at Days 46-50 indicates that this transient increase in chorionic surface area confers no very obvious benefit to the developing fetus.

\section{References}

Day, B.N., Anderson, L.L., Emmerson, M.A., Hazel, L.M. \& Melampy, R.M. (1959) Effect of estrogen and progesterone on early embryonic mortality in ovariectomized gilts. J. Anim. Sci. 18, 607-613.

Haines, C.E., Warnick, A.C. \& Wallace, H.D. (1958) The effect of exogenous progesterone and level of feeding on prenatal survival in gilts. J. Anim. Sci. 17, 879-885.
Knight, J.W., Bazer, F.W. \& Wallace, H.D. (1974) Effect of progesterone induced increase in uterine secretory activity on development of the porcine conceptus. J. Anim. Sci. 39, 743-746.

Knight, J.W., Bazer, F.W., Thatcher, W.R., Franks, D.E. \& Wallace, H.D. (1977) Conceptus development in intact and unilaterally hysterectomized-ovariectomized gilts: interrelations among hormonal 
status, placental development, fetal fluids and fetal growth. J. Anim. Sci. 44, 620-637.

Reddy, V.B., Mayer, C.T. \& Lasley, J.F. (1958) Hormonal modification of the intra-uterine environment in swine and its effect on embryonic viability. Univ. Missouri Res. Bull. No. 667, pp. 4-31.

Sammelwitz, P.H., Dziuk, P.J. \& Nalbandov, A.V. (1956) Effects of progesterone on embryonal mortality of rats and swine. J. Anim. Sci. 15, 1211-1212.
Spies, H.G., Zimmerman, D.R., Self, H.L. \& Casida, L.E. (1959) The effect of exogenous progesterone on formation and maintenance of the corpora lutea and on early embryo survival in pregnant swine. J. Anim. Sci. 18, 163-172.

Wildt, D.E., Culver, A.A., Morcom, C.B. \& Dukelow, W.R. (1976) Effect of administration of progesterone and oestrogen on litter size in pigs. $J$. Reprod. Fert. 48, 209-211.

Received 3 July 1980 